\title{
Actuator Structure Analysis Using New Electro-Thermo-Mechanical Finite Element for Functionally Graded Materials
}

\author{
Juraj Paulech*, Vladimír Kutiš, Justín Murín*, Gabriel Gálik* and Vladimír Goga* \\ * Department of Applied Mechanics and Mechatronics \\ Institute of Automotive Mechatronics \\ Faculty of Electrical Engineering and Information Technology \\ Slovak University of Technology \\ Ilkovicova 3, 81219 Bratislava, Slovak Republic \\ e-mail: juraj.paulech@stuba.sk, web page: http://www.cimne.upc.edu
}

\begin{abstract}
Functionally Graded Materials (FGMs) are new types of material where their properties vary spatially according to chosen function to reach such features that are unable to provide using standard materials or composites. Hence, a structure made of FGM can dispose for example with excellent thermal conductivity at one component part together with thermal insulating properties at another component part.

Proposed paper deals with electro-thermo-mechanical analysis of chosen actuator structure made od FGM using new finite element derived specially for this purpose. Rectangular crosssection of individual beams that form the von Mises structure with variation of material properties in longitudinal and lateral direction will be considered. Actuator action, electric voltage and temperature peak and also mechanical stress of the structure will be evaluated. Results from the analysis calculated using our new FGM beam finite elements will be compared to results from conventional FEM analysis where standard finite elements will be used.
\end{abstract}

\section{ACKNOWLEDGEMENT}

This work was supported by the Slovak Grant Agency: VEGA No. 1/0081/18, KEGA 011STU-4/2020 and APVV-19-0406.

\section{REFERENCES}

[1] J. Murín et. al., Electric-Thermal Link Finite Element Made of a FGM with Spatial Variation of Material Properties. Composites Part B: Engineering, Vol. 42, pp. 1966-1979. 2011.

[2] J. Paulech et. al., Analysis of functionally graded material actuator using new finite elements. Coupled problems 2019, Spain, pp. 413-421. 2019.

[3] J. Murín and V. Kutiš, An Effective Multilayered Sandwich Beam-Link Finite Element for Solution of the Electro-Thermo-Structural Problems. Computers and Structures. Vol. 87, pp. 1496-1507. 2009. 